Acta Crystallographica Section A

Foundations and

Advances

ISSN 2053-2733

\section{The wingspan of mathematical crystallography}

\author{
Massimo Nespolo ${ }^{a}$ and Gregory McColm ${ }^{b}$
}

aUniversité de Lorraine, Faculté des Sciences et Technologies, Institut Jean Barriol FR 2843, CRM2 UMR CNRS 7036, BP 70239, Boulevard des Aiguillettes, F-54506 Vandoeuvre-lès-Nancy cedex, France, and ${ }^{\mathbf{b}}$ Mathematics and Statistics, University of South Florida, 4202 E. Fowler Avenue, CMC 342, Tampa, Florida 33620, USA

Crystallography is a natural area for the collaboration of physical science and mathematics. Much of 'mathematical crystallography' arose during the 19th century from the work of mathematicians, mineralogists, physicists and chemists. It was, and is again, a genuinely interdisciplinary field. Moreover, the growing demand for materials in general, and crystals in particular, will entail a growing need for an expanded mathematical toolkit. Whatever the advances in packaging software for non-mathematically inclined users, mastery of a mathematical toolkit requires a good understanding of the mathematics.

Such considerations led to the formation of a MaThCryst 'workgroup' in 2002, which the 20th IUCr Congress in Florence transformed into the Commission on Mathematical and Theoretical Crystallography in August 2005. The MaThCryst workgroup had organized a school in Nancy that June, and from that event came a special issue on Mathematical Crystallography in Acta Crystallographica Section $A$ in March 2006 (Volume 62, Part 2). Since then, the MaThCryst Commission has organized and participated in many activities all over the world.

In particular, the lack of a solid education in fundamental crystallography among chemists, crystallographers, physicists and other participants prompted the Commission to develop itinerant schools, which are becoming a tradition. As this editorial goes to press, the fourth MaThCryst school in Latin America will be over and plans for the fifth are already advanced. The second school in South Africa will convene soon after the 23rd IUCr Congress in Montreal.

The Commission also organizes more advanced and specific schools, partly in cooperation with other commissions. Topics range from topological methods in crystallography (Nancy 2010, Samara 2014) to irreducible representations of space groups (Nancy 2010) to electron crystallography (Antwerp 2016) to graph theory.

MaThCryst plans four activities this year. For details, see the MaThCryst website at http://www.crystallography.fr/mathcryst.

The Commission also organizes satellite conferences and workshops all over the world. A recent and fruitful cooperation with US mathematicians has resulted in crystallographic special sessions at sectional meetings of the American Mathematical Society and specialized conferences of the Society for Industrial and Applied Mathematics. In particular, the 2013 SIAM Conference on Mathematical Aspects of Materials Science in Philadelphia was the occasion to gather articles, partly issued from that meeting, for this second special issue on Mathematical Crystallography in Acta Crystallographica Section A. Perhaps befitting this digital age, this is a virtual issue, spanning three regular issues, but all appearing during the International Year of Crystallography. The result is a wide but necessarily incomplete selection from the panorama of research activities.

G. McColm introduces this virtual issue with an article on Prospects for mathematical crystallography, where the potential of mathematical crystal- 
lography as an emerging field is examined from a sociological point of view, with a detailed and precise bibliographical analysis.

Next is a series of papers on three-dimensional and Euclidean crystallography. M. I. Aroyo et al. present the database of Brillouin zones at the Bilbao Crystallographic Server, a free collection of tools and software routines which have become indispensable companions of every crystallographer willing or needing to go beyond the daily structural work. M. Nespolo et al. provide criteria to determine or exclude the presence of merohedric twinning from the geometry and intensities of a diffraction pattern. E. Schulte presents the geometric, combinatorial and algebraic properties of skeletal polyhedra and polygonal complexes which can be used to describe and classify crystal structures. M. Moreira de Oliveira and J.-G. Eon go further in a similar direction and discuss crystal structures whose topology corresponds to periodic nets characterized by noncrystallographic automorphism groups.

The remaining papers guide the reader in spaces differing by their dimensions or their geometry. D. B. Litvin analyses the physical properties of quasi-onedimensional materials, such as nanotubes or polymers, via the form of the corresponding tensors. M.
Quiquandon et al. present the basic tools for the description of atomic structures of quasicrystals, with special emphasis on icosahedral phases. S. T. Hyde et al. present the orbifold topological approach to symmetric patterns and crystallography by employing non-Euclidean (hyperbolic) geometry.

We are confident that this virtual issue demonstrates the actuality and the importance of mathematical crystallography for every researcher interested in the periodic structure of matter, whatever the dimension and geometry.

\section{References}

Aroyo, M. I., Orobengoa, D., de la Flor, G., Tasci, E. S., Perez-Mato, J. M. \& Wondratschek, H. (2014). Acta Cryst. A70, 126-137.

Hyde, S. T., Ramsden, S. J. \& Robins, V. (2014). Acta Cryst. A70, 319337.

Litvin, D. B. (2014). Acta Cryst. A70, 138-142.

McColm, G. (2014). Acta Cryst. A70, 95-105.

Moreira de Oliveira, M. Jr \& Eon, J.-G. (2014). Acta Cryst. A70, $217-$ 228.

Nespolo, M., Ferraris, G. \& Souvignier, B. (2014). Acta Cryst. A70, 106-125.

Quiquandon, M., Portier, R. \& Gratias, D. (2014). Acta Cryst. A70, 229-238.

Schulte, E. (2014). Acta Cryst. A70, 203-216. 